\title{
Article \\ Systematic Observation of Corner Kick Strategies in Portuguese Football Players
}

\author{
Vítor Gouveia ${ }^{1,2}$, João P. Duarte ${ }^{1}\left(\mathbb{D}\right.$, Hugo Sarmento ${ }^{1}\left(\mathbb{D}\right.$, José Freitas ${ }^{2}$, Ricardo Rebelo-Gonçalves ${ }^{1,2} \mathbb{C}^{\circledR}$,

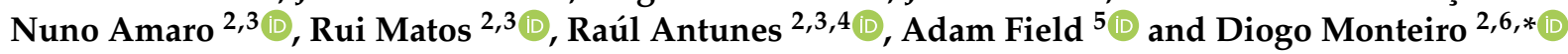

check for

updates

Citation: Gouveia, V.; Duarte, J.P.;

Sarmento, H.; Freitas, J.;

Rebelo-Gonçalves, R.; Amaro, N.;

Matos, R.; Antunes, R.; Field, A.;

Monteiro, D. Systematic Observation

of Corner Kick Strategies in

Portuguese Football Players.

Sustainability 2022, 14, 896. https:/ /

doi.org/10.3390/su14020896

Academic Editors:

Antonio Hernández-Mendo,

Coral Falco, Verónica Morales-

Sánchez, Cristina Menescardi,

Tomas Herrera-Valenzuela and

Alexandre Garcia-Mas

Received: 2 November 2021

Accepted: 12 January 2022

Published: 13 January 2022

Publisher's Note: MDPI stays neutral with regard to jurisdictional claims in published maps and institutional affiliations.

Copyright: (C) 2022 by the authors. Licensee MDPI, Basel, Switzerland. This article is an open access article distributed under the terms and conditions of the Creative Commons Attribution (CC BY) license (https:// creativecommons.org/licenses/by/ $4.0 /)$.
1 University of Coimbra, Research Unit for Sport and Physical Activity, Faculty of Sport Sciences and Physical Education, Coimbra 3040-248, Portugal; vitor.gouveia@ipleiria.pt (V.G.); joaopedromarquesduarte@gmail.com (J.P.D.); hugo.sarmento@uc.pt (H.S.); ricardo.r.goncalves@ipleiria.pt (R.R.-G.)

2 ESECS—Polytechnic of Leiria, 2411-901 Leiria, Portugal; miguelfreitasmf26@gmail.com (J.F.); nuno.amaro@ipleiria.pt (N.A.); rui.matos@ipleiria.pt (R.M.); raul.antunes@ipleiria.pt (R.A.)

3 Life Quality Research Centre (CIEQV), 2411-901 Leiria, Portugal

4 ciTechCare, Polytechnic of Leiria, Campus 2-Morro do Lena, Alto do Vieiro, 2411-901 Leiria, Portugal

5 School of Human and Health Sciences, University of Huddersfield, Huddesfield HD1 3DH, UK; adam.field@hud.ac.uk

6 Research Center in Sports Sciences, Health Sciences and Human, Development (CIDESD), 5001-801 Vila Real, Portugal

* Correspondence: diogo.monteiro@ipleiria.pt

\begin{abstract}
Set pieces are important for the success of football teams, with the corner kick being one of the most game defining events. The aim of this research was twofold: (1) to analyze the corner kicks of a senior football amateur team, and (2) to compare the corner kicks of successful and unsuccessful teams (of the 2020/21 sporting season). In total, 500 corners were observed using a bespoke notational analysis tool, using a specific observational instrument tool (8 criteria; 25 categories). Out of the 500 corner kicks, $6 \%$ resulted in a goal. A greater number of direct corners using inswing trajectories were performed $(n=54 \%)$. Corners were delivered to central and front post areas most frequently $(n=79 \%)$. Five attackers were most predominantly used for offensive corners $(n=58 \%)$, but defenders won the ball more frequently $(n=44 \%)$. Attempts at goal occurred following a corner most commonly from outside of the box $(n=7 \%)$. Goals were scored most frequently with the foot $(n=16 \%)$ and head $(n=15 \%)$. Successful teams are more effective at reaching the attackers and score more goals directly from corners. Unsuccessful teams deliver more corner kicks out of play, the first touch is more frequently from the opposition defenders, and fewe goals are scored from corner kicks. The study provides an insight into the determining factors and patterns that influence corner kicks and success in football matches. This information should be used by coaches to prepare teams for both offensive and defensive corner kicks to increase team success and match outcomes.
\end{abstract}

Keywords: set pieces; soccer; performance analysis; match analysis; team sports; observational methodology

\section{Introduction}

The performance analysis of different elements of football match play is growing in sports science research [1-3]. In a low scoring team sport such as soccer [4], goals have an integral influence on match outcomes and are a key determinant to success. Set pieces account for a large proportion of goals in male elite soccer, with $39.1 \%$ in the 2018 FIFA World Cup [5], 24.1\% in the UEFA Champions League [6], 30.6\% in the MLS [7] and $24 \%$ in the 2010 FIFA World Cup [8]. Set pieces can occur in several forms, such as free kicks, corners, penalties, and throw ins. Growing research attention has been afforded to understanding various forms of set pieces, including their effectiveness, patterns and trends [9-11]. Corner kicks are one form of set play and are awarded when the whole of the ball passes over the goal line, having last touched a defending player. Corner kicks 
provide more goal scoring opportunities than other set pieces [12], thus, can often be a determining factor in the outcome of a match [13-16]. Typically, there are about 10 corners per match [14-16], with between $2 \%$ and $4 \%$ resulting in goals [13,15-19].

Corner kicks have been studied from different perspectives in recent years, for instance, the influence of match status $[18,20]$, the possible home advantage and/or time of occurrence $[19,21]$, the description of technical and tactical options (i.e., type of trajectory, area of delivery), attacking and defensive organization $[13,15,22,23]$, and defensive approaches [24-26]. However, despite the growing evidence base documenting various aspect of corner kicks, few studies have analyzed different strategies and how these compare between successful and unsuccessful teams. One investigation, [16], studied corner kicks to observe different outcomes according to their final league positions and found that the goals scored from corners were $9.3 \%$ for the top six teams whilst the bottom six teams scored from $14.1 \%$ of corners. Interestingly, the study also demonstrated that the top six teams used the foot for attempts at goal, used more outswing deliveries, and presented a dynamic attacking organization. The bottom six teams used the right foot to deliver more predominantly, with mainly inswing trajectories. It was also found that both groups delivered the ball directly to the penalty area and near the goal and goalpost. However, to the best of our knowledge, there is an absence of research that has evaluated corner kick strategies in Portuguese football teams. Given the difference in tactical approaches across varying countries, this research is required to gain a comprehensive depiction of how corner kick patterns in Portuguese teams compare to teams in other countries and leagues.

On the other hand, all the above forementioned research studies used as a sample professional competition, which are estimated to include around 128,983 players [24] in an estimated universe of 250,000,000 amateur or recreational, male, or female, from different age groups. To the best of our knowledge, there are no published studies on this subject with semiprofessional or amateur teams. Bearing in mind that it is in these teams that most of the young players and coaches are found who are in transition to higher competitive levels, the knowledge of these specific characteristics of the game can be an asset for those who intend to reach another level of performance.

Observational methodology has been an important resource that coaches and scientists have utilized over the past years to improve performance analysis in football [25-28]. The game of football is characterized by great complexity, which makes it difficult to objectify its observation and analysis [29]. In this sense, to overcome the usual limitations found in "traditional" investigations, an increase in the amount of research on game action in football has been observed, based on observational methodology [30-32].

Therefore, the aims of this study were: (1) to describe how corner kicks are performed in national level championship teams; and (2) to differentiate the corner kick patterns and strategies between successful and unsuccessful teams.

\section{Materials and Methods}

\subsection{Match Sample}

The Portugal Championship (Campeonato de Portugal) is mainly an amateur competition (3rd national division) which, in the 2020/21 season, gave access to the Second League or to the Third League (a new competition). It was constituted by 2 phases: in the first, 8 groups of 12 teams with the first four being ranked to the second phase; in the second phase, 8 groups of 4 teams aimed to fight for promotion to the Second or Third League. The groups were organized from North to South. A convenience sample of 500 corner kicks was chosen from the second phase of the competition, from which 250 were from the teams that placed in the first 2 places and were promoted (successful teams) and 250 from the teams that were not promoted (unsuccessful teams). The corners were analyzed from a performance analysis database (InStat, Dublin, Ireland). The corners were randomly selected from the groups and the inclusion criteria specified that the image quality was sufficient for robust conclusions to be formed as a result of viewing the footage. The local university ethics committee granted approval for the study. 


\subsection{Measures and Procedures}

The data were collected using a spread sheet created in Microsoft Office Excel (Version 16.5, Microsoft Corporation, Redmond, WA, USA). It was used as a notational analysis tool that was built by a panel of experts comprising two UEFA PRO licensed football coaches, using several performance indicators considered important in corner kicks from a practical point of view. All the criteria of each variable and respective descriptors were discussed and then defined to increase clarity and minimize misinterpretations when analyzing the data (Table 1). Eight variables were chosen to perform the analysis (Figure 1). The "corner side" was defined as the side at which the attacking team's corner kick took place (left or right). The second, "type of delivery" related to the style of corner performed by the attacking team (direct outswing, direct inswing, short or others). The third variable, "zone of the delivery" (Figure 1) was described as the area in which the ball was first contacted or not contacted following the corner delivery, relating to a number of predefined areas (goal area-GA1 and 2; penalty area-PA1 and 2; lateral zone-LZ1 and 2; OB-out of the box; "other zone" and "outside"). If the ball was delivered directly to the outside of the pitch it was considered "out or loss of the ball". The "short delivery" was characterized as the ball being touched towards a teammate near the kicker. It must be noted that when the ball was delivered and reached one of the defined zones following a "short delivery", then this was included in the "zone of delivery" analyses. The "number of attackers" variable aims to register the players who effectively try to attack finalization zones with the intention of scoring. The "player of the first touch" describes the player who first touches the ball following the corner kick ("attacker", "defender", "goalkeeper" and" other"). The "finalization zone" is characterized by the area in which an attempt at goal is made (refer to "zone of delivery" for each of the zones). "No finalization" is defined by no shot at goal being achieved following the corner kick. Each corner was analyzed from the moment that ball was touched until the end of the play, which was considered when at least one of the following events occurred: (i) the ball left the pitch; (ii) the defending team won the ball or the attacking team scored; and (iii) when both teams lose their specific formation for the corner kick (i.e., when the phase of play for the corner kick naturally terminates and open play resumes).

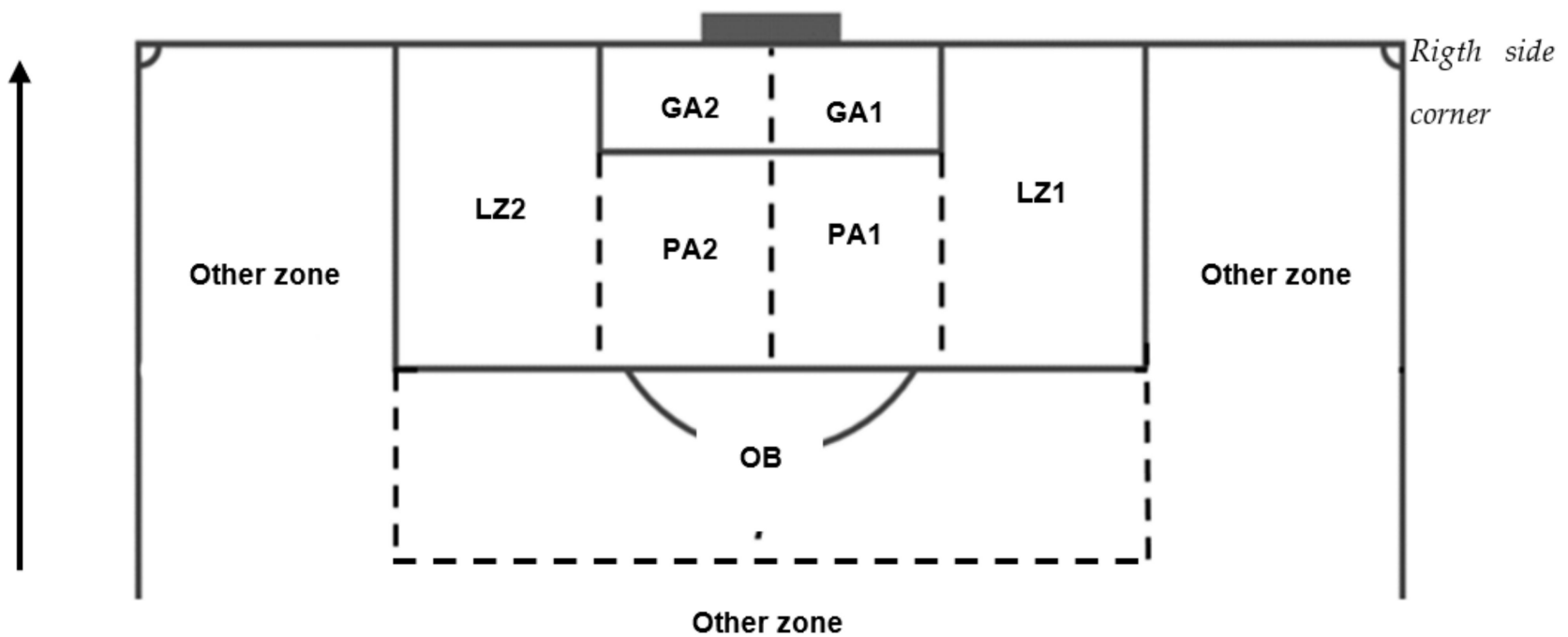

Figure 1. Example of the defined zones for the first ball and finalization for a corner kick from the right side. From the left side, the zones change accordingly, for instance, zone LZ1 is nearer the corner side. Same for the other areas (GA1 to PA1). 
Table 1. Observation tool used in this study with the performance indicators and their respective descriptions.

\begin{tabular}{|c|c|}
\hline Criteria & Categories and Definition \\
\hline \multirow[t]{2}{*}{ Corner side } & $\begin{array}{l}\text { Right: The corner is awarded on the right side of the attacking team. } \\
\text { Left: The corner is awarded on the left side of the attacking team. }\end{array}$ \\
\hline & $\begin{array}{c}\text { Direct outswing: The ball is kicked and enters directly (on the first touch) with an open } \\
\text { trajectory, i.e., spinning away from the goal. }\end{array}$ \\
\hline \multirow[t]{4}{*}{ Deliver type } & $\begin{array}{c}\text { Direct inswing: The ball is kicked and enters directly with a closed trajectory, i.e., spinning } \\
\text { away from the goal. }\end{array}$ \\
\hline & Short corner: The ball enters in one of the defined zones indirectly. \\
\hline & $\begin{array}{l}\text { Others: This category includes (i) corners kicked directly to one of the zones and with a flat or a } \\
\text { loop trajectory, (ii) corners kicked directly to one of the zones using a ground pass seeking an } \\
\text { immediate finish, and (iii) any other corner which does not fit in any other category. }\end{array}$ \\
\hline & $\begin{array}{l}\text { Zone } 1 \text { to } 7 \text { : where the ball was touched for the first time directly or following a short corner } \\
\text { (see Figure 1). }\end{array}$ \\
\hline \multirow[t]{2}{*}{ Zone of the first touch } & Other zone: The ball was touched in any other area which is not defined above. \\
\hline & $\begin{array}{c}\text { Out or loss of the ball: the ball was played directly to the outside of the pitch or the ball was lost } \\
\text { after a short corner without entering in one of the defined zones. }\end{array}$ \\
\hline \multirow[t]{2}{*}{ Number of attackers } & $\begin{array}{c}4 \text { or fewer, 5, 6, more than } 7 \text { players in position and with the intention of attacking the } \\
\text { finalization zones. }\end{array}$ \\
\hline & $\begin{array}{l}\text { Attacker: A player of the attacking team is the first to touch the ball after it enters in a zone. } \\
\text { Defender: A player of the defending team is the first to touch the ball after it enters in a zone } \\
\text { excluding the goalkeeper. }\end{array}$ \\
\hline \multirow[t]{2}{*}{ Player of the first touch } & Goalkeeper: The GK from the defending team. \\
\hline & $\begin{array}{l}\text { Other: The ball (i) enters directly in the goal without touching any player, (ii) the ball goes } \\
\text { directly out of the pitch, or (iii) a foul is committed before any player touches the ball. } \\
\text { Zone: There was a shot in one of the zones GA1, GA2, PA1, PA2, LZ1, LZ2 and OB. }\end{array}$ \\
\hline \multirow[t]{3}{*}{ Finalization zone } & Other zone: There was a shot in another zone, excluding the ones mentioned above. \\
\hline & No finalization: There was no finalization during the sequence of the corner. \\
\hline & $\begin{array}{l}\text { Head: The attempt was performed with the head. } \\
\text { Foot: The shot was performed with the foot. }\end{array}$ \\
\hline Type of finalization & $\begin{array}{l}\text { Other body part: The shot was performed with other body part, within the laws of the game. } \\
\text { No finalization: The corner did not result in finalization. }\end{array}$ \\
\hline \multirow{2}{*}{ Outcome } & Goal: A goal was obtained from the corner kick. \\
\hline & No goal: The corner kick did not result in a goal. \\
\hline
\end{tabular}

\subsection{Reliability Testing}

To assure data accuracy and the reliability of the performance indicators, two soccer specialists were trained to understand how to quantify the corner kick data. They were trained in two different sessions to work with the chosen variables and to clarify possible doubts and/or misunderstandings. To assess interobserver reliability, both observers analyzed the same 100 corners.

Reliability was calculated using the technical error of measurement (TEM) [33], intraclass correlations (ICCs) and coefficient of variation (CV). The reliability data is presented in Table 2 . The reliability values ranged from 0 to 1 ; ICC $<0$ indicates "no reliability", ICC $\geq 0$ and $<0.2$ "light reliability", 0.2 to $<0.4$ "reasonable reliability", 0.4 to $<0.6$ "moderate reliability", 0.6 to $<0.8$ "substantial reliability", and from 0.8 to $<1$ "almost perfect reliability" [34]. The CV was expressed as a percentage of the mean and generally CV's $\leq 5 \%$ indicated good reliability, whilst CV's $\geq 10 \%$ did not [35]. 
Table 2. Data control and quality.

\begin{tabular}{cccc}
\hline Variable & TEM $^{\mathbf{1}}$ & ICC $^{\mathbf{1}}$ & CV (\%) $^{\mathbf{1}}$ \\
\hline Corner side & 0.00 & 1.000 & 0.00 \\
Deliver type & 1.27 & 0.998 & 5.07 \\
Zone of the first touch & 1.05 & 0.990 & 9.49 \\
Number of attackers & 5.12 & 0.958 & 20.49 \\
Player of the first touch & 1.80 & 0.983 & 7.21 \\
Finalization zone & 0.47 & 0.999 & 4.24 \\
Type of finalization & 0.50 & 0.999 & 2.00 \\
Outcome & 0.00 & 1.000 & 0.00 \\
\hline
\end{tabular}

${ }^{1}$ Abbreviations: TEM (technical error of measurement); ICC (intraclass correlation); CV (coefficient of variation).

\subsection{Statistical Analysis}

Descriptive statistics (means, standards deviations and relative frequencies) of the selected variables were calculated. For between groups comparisons, an independent samples $t$-test was used. The magnitude of the effects was interpreted as follows [36]: $<0.20$ (trivial); 0.20 to 0.59 (small); 0.60 to 1.19 (moderate); 1.20 to 1.99 (large); 2.00 to 3.99 (very large); $\geq 4.00$ (extremely large). The level of significance was established as $p<0.05$. All analyses were performed using the statistical software Statistical Package for the Social Sciences, version 26 (SPSS Inc., IBM Company, Armonk, NY, USA).

\section{Results}

3.1. Descriptive Analysis

The corner kick data are displayed in Table 3.

Table 3. Descriptive statistics for the total number of corners analyzed.

\begin{tabular}{|c|c|c|c|c|c|c|}
\hline & \multicolumn{2}{|c|}{ Total } & \multicolumn{4}{|c|}{ Group } \\
\hline & \multirow{2}{*}{$\#(n=500)$} & \multirow{2}{*}{$\%$} & \multicolumn{2}{|c|}{ Successful } & \multicolumn{2}{|c|}{ Unsuccessful } \\
\hline & & & $\#(n=250)$ & $\%$ & $\#(n=250)$ & $\%$ \\
\hline \multicolumn{7}{|l|}{ Corner side } \\
\hline Right & 298 & $60 \%$ & 145 & $58 \%$ & 153 & $61 \%$ \\
\hline Left & 202 & $40 \%$ & 105 & $42 \%$ & 97 & $39 \%$ \\
\hline \multicolumn{7}{|l|}{ Delivery type } \\
\hline Direct outswing & 137 & $27 \%$ & 71 & $28 \%$ & 66 & $26 \%$ \\
\hline Direct inswing & 271 & $54 \%$ & 136 & $54 \%$ & 135 & $54 \%$ \\
\hline Short corner & 75 & $15 \%$ & 34 & $14 \%$ & 41 & $16 \%$ \\
\hline Others & 17 & $3 \%$ & 9 & $4 \%$ & 8 & $3 \%$ \\
\hline \multicolumn{7}{|c|}{ Zone of the first touch ${ }^{2}$} \\
\hline GA1 & 175 & $35 \%$ & 79 & $32 \%$ & 96 & $38 \%$ \\
\hline GA2 & 77 & $15 \%$ & 44 & $18 \%$ & 33 & $13 \%$ \\
\hline PA1 & 74 & $15 \%$ & 41 & $16 \%$ & 33 & $13 \%$ \\
\hline PA2 & 71 & $14 \%$ & 34 & $14 \%$ & 37 & $15 \%$ \\
\hline LZ1 & 38 & $8 \%$ & 22 & $9 \%$ & 16 & $6 \%$ \\
\hline LZ2 & 23 & $5 \%$ & 12 & $5 \%$ & 11 & $4 \%$ \\
\hline OB & 9 & $2 \%$ & 7 & $3 \%$ & 2 & $1 \%$ \\
\hline Other zone & 8 & $2 \%$ & 5 & $2 \%$ & 3 & $1 \%$ \\
\hline Outside & 25 & $5 \%$ & 6 & $2 \%$ & 19 & $8 \%$ \\
\hline
\end{tabular}


Table 3. Cont.

\begin{tabular}{|c|c|c|c|c|c|c|}
\hline & \multicolumn{2}{|c|}{ Total } & \multicolumn{4}{|c|}{ Group } \\
\hline & \multirow{2}{*}{$\#(n=500)$} & \multirow{2}{*}{$\%$} & \multicolumn{2}{|c|}{ Successful } & \multicolumn{2}{|c|}{ Unsuccessful } \\
\hline & & & $\#(n=250)$ & $\%$ & $\#(n=250)$ & $\%$ \\
\hline \multicolumn{7}{|l|}{ Number of attackers } \\
\hline 4 or less & 69 & $14 \%$ & 29 & $12 \%$ & 40 & $16 \%$ \\
\hline 5 & 292 & $58 \%$ & 140 & $56 \%$ & 152 & $61 \%$ \\
\hline 6 & 130 & $26 \%$ & 74 & $30 \%$ & 56 & $22 \%$ \\
\hline More than 7 & 9 & $2 \%$ & 7 & $3 \%$ & 2 & $1 \%$ \\
\hline \multicolumn{7}{|l|}{ Player of the first touch } \\
\hline Attacker & 157 & $31 \%$ & 90 & $36 \%$ & 67 & $27 \%$ \\
\hline Defender & 222 & $44 \%$ & 98 & $39 \%$ & 124 & $50 \%$ \\
\hline Goalkeeper & 79 & $16 \%$ & 47 & $19 \%$ & 32 & $13 \%$ \\
\hline Direct/outsider/fault & 42 & $8 \%$ & 15 & $6 \%$ & 27 & $11 \%$ \\
\hline \multicolumn{7}{|l|}{ Finalization zone } \\
\hline GA1 & 31 & $6 \%$ & 13 & $5 \%$ & 18 & $7 \%$ \\
\hline GA2 & 16 & $3 \%$ & 12 & $5 \%$ & 4 & $2 \%$ \\
\hline PA1 & 30 & $6 \%$ & 16 & $6 \%$ & 14 & $6 \%$ \\
\hline PA2 & 30 & $6 \%$ & 16 & $6 \%$ & 14 & $6 \%$ \\
\hline LZ1 & 2 & $0 \%$ & 1 & $0 \%$ & 1 & $0 \%$ \\
\hline LZ2 & 7 & $1 \%$ & 3 & $1 \%$ & 4 & $2 \%$ \\
\hline OB & 37 & $7 \%$ & 21 & $8 \%$ & 16 & $6 \%$ \\
\hline Other zone & 3 & $1 \%$ & 2 & $1 \%$ & 1 & $0 \%$ \\
\hline No finalization & 344 & $69 \%$ & 166 & $66 \%$ & 178 & $71 \%$ \\
\hline \multicolumn{7}{|l|}{ Type of finalization } \\
\hline Head & 77 & $15 \%$ & 43 & $17 \%$ & 34 & $14 \%$ \\
\hline Foot & 80 & $16 \%$ & 42 & $17 \%$ & 38 & $15 \%$ \\
\hline No finalization & 343 & $69 \%$ & 165 & $66 \%$ & 178 & $71 \%$ \\
\hline \multicolumn{7}{|l|}{ Outcome } \\
\hline Goal & 29 & $6 \%$ & 20 & $8 \%$ & 9 & $4 \%$ \\
\hline No goal & 471 & $94 \%$ & 230 & $92 \%$ & 241 & $96 \%$ \\
\hline
\end{tabular}

2 Abbreviations: GA (goal area); PA (penalty area); LZ (lateral zone); OB (out of the box).

\subsection{Groups Comparison}

Between group comparison data for successful and unsuccessful teams are reported in Table 4. Successful teams have greater effectiveness in taking corner kicks that reach the attackers $(0.36 \pm 0.48$ vs. $0.27 \pm 0.44 ; p=0.022)$. These teams also deliver more often into the GA2 zone ( $0.05 \pm 0.21$ vs. $0.02 \pm 0.13 ; p=0.032)$ and have more goals scored directly benefiting from these set pieces. Unsuccessful teams delivered more corner kicks directly to the outside of the pitch when compared with successful teams $(0.08 \pm 0.27 \mathrm{vs} .0 .02 \pm 0.15$; $p=0.009$ ). Opposition defenders perform the first touch of the ball more frequently when unsuccessful teams take corner kicks ( $0.50 \pm 0.50$ vs. $0.39 \pm 0.49, p=0.018)$. Unsuccessful teams score less from corner kicks $(0.96 \pm 0.19$ vs. $0.92 \pm 0.27 ; p=0.034)$. 
Table 4. Means comparison between the two groups: successful (1st and 2nd places) and unsuccessful (3rd and 4 th places).

\begin{tabular}{|c|c|c|c|c|c|c|c|}
\hline \multirow{2}{*}{ Variables } & \multicolumn{3}{|c|}{ Group } & \multicolumn{2}{|c|}{ Student $t$-Test } & \multicolumn{2}{|c|}{ Magnitude Effects } \\
\hline & Successful & Unsuccessful & Means Differences & $t$ & $P$ & $d$ & (Qualitative) \\
\hline \multicolumn{8}{|l|}{ Corner side } \\
\hline Rigth & $0.58 \pm 0.49$ & $>0.61 \pm 0.49$ & -0.03 & -0.718 & 0.474 & 0.06 & (trivial) \\
\hline Left & $0.42 \pm 0.49$ & $0.39 \pm 0.49$ & 0.03 & 0.718 & 0.474 & 0.06 & (trivial) \\
\hline \multicolumn{8}{|l|}{ Delivery type } \\
\hline Direct outswing & $0.28 \pm 0.45$ & $0.26 \pm 0.44$ & 0.02 & 0.502 & 0.616 & 0.05 & (trivial) \\
\hline Direct inswing & $0.54 \pm 0.50$ & $0.54 \pm 0.50$ & 0.00 & 0.087 & 0.931 & 0.00 & (trivial) \\
\hline Short corner & $0.14 \pm 0.34$ & $0.16 \pm 0.37$ & -0.02 & -0.882 & 0.379 & 0.06 & (trivial) \\
\hline Others & $0.04 \pm 0.19$ & $0.03 \pm 0.18$ & 0.01 & 0.242 & 0.809 & 0.05 & (trivial) \\
\hline \multicolumn{8}{|l|}{ Zone of the first touch ${ }^{3}$} \\
\hline GA1 & $0.32 \pm 0.47$ & $0.38 \pm 0.49$ & -0.06 & -1.501 & 0.135 & 0.13 & (trivial) \\
\hline GA2 & $0.18 \pm 0.38$ & $0.13 \pm 0.34$ & 0.05 & 1.388 & 0.166 & 0.14 & (trivial) \\
\hline PA1 & $0.16 \pm 0.37$ & $0.13 \pm 0.34$ & 0.03 & 1.000 & 0.318 & 0.09 & (trivial) \\
\hline PA2 & $0.14 \pm 0.34$ & $0.15 \pm 0.36$ & -0.01 & -0.377 & 0.706 & 0.03 & (trivial) \\
\hline $\mathrm{LZ1}$ & $0.09 \pm 0.28$ & $0.06 \pm 0.25$ & 0.03 & 1.000 & 0.318 & 0.11 & (trivial) \\
\hline LZ2 & $0.05 \pm 0.21$ & $0.04 \pm 0.21$ & 0.01 & 0.218 & 0.828 & 0.05 & (trivial) \\
\hline OB & $0.03 \pm 0.17$ & $0.01 \pm 0.09$ & 0.02 & 1.673 & 0.096 & 0.15 & (trivial) \\
\hline Other zone & $0.02 \pm 0.14$ & $0.01 \pm 0.11$ & 0.01 & 0.816 & 0.415 & 0.08 & (trivial) \\
\hline Outside & $0.02 \pm 0.15$ & $0.08 \pm 0.27$ & -0.06 & -2.631 & 0.009 * & 0.28 & (small) \\
\hline \multicolumn{8}{|l|}{ Number of attackers } \\
\hline 4 or less & $0.12 \pm 0.32$ & $0.16 \pm 0.37$ & -0.04 & -1.435 & 0.153 & 0.12 & (trivial) \\
\hline 5 & $0.56 \pm 0.50$ & $0.61 \pm 0.49$ & -0.05 & -1.096 & 0.274 & 0.10 & (trivial) \\
\hline 6 & $0.30 \pm 0.46$ & $0.22 \pm 0.42$ & 0.08 & 1.866 & 0.063 & 0.18 & (trivial) \\
\hline More than 7 & $0.03 \pm 0.17$ & $0.01 \pm 0.09$ & 0.02 & 1.673 & 0.096 & 0.15 & (trivial) \\
\hline \multicolumn{8}{|l|}{ Player of the first touch } \\
\hline Attacker & $0.36 \pm 0.48$ & $0.27 \pm 0.44$ & 0.09 & 2.308 & $0.022 *$ & 0.20 & (small) \\
\hline Defender & $0.39 \pm 0.49$ & $0.50 \pm 0.50$ & -0.11 & -2.376 & 0.018 * & 0.23 & (small) \\
\hline Goalkeeper & $0.19 \pm 0.39$ & $0.13 \pm 0.33$ & 0.06 & 1.870 & 0.063 & 0.17 & (trivial) \\
\hline Direct/outsider/fault & $0.06 \pm 0.24$ & $0.11 \pm 0.31$ & -0.05 & -1.958 & 0.051 & 0.18 & (trivial) \\
\hline \multicolumn{8}{|l|}{ Finalization zone } \\
\hline GA1 & $0.05 \pm 0.22$ & $0.07 \pm 0.26$ & -0.02 & -0.898 & 0.370 & 0.08 & (trivial) \\
\hline GA2 & $0.05 \pm 0.21$ & $0.02 \pm 0.13$ & 0.03 & 2.154 & $0.032 *$ & 0.13 & (trivial) \\
\hline PA1 & $0.06 \pm 0.25$ & $0.06 \pm 0.23$ & 0.00 & 0.377 & 0.706 & 0.00 & (trivial) \\
\hline PA2 & $0.06 \pm 0.25$ & $0.06 \pm 0.23$ & 0.00 & 0.365 & 0.716 & 0.00 & (trivial) \\
\hline LZ1 & $0.01 \pm 0.06$ & $0.01 \pm 0.06$ & 0.00 & 0.000 & 1.000 & 0.00 & (trivial) \\
\hline LZ2 & $0.01 \pm 0.11$ & $0.02 \pm 0.13$ & 0.01 & -0.377 & 0.706 & 0.08 & (trivial) \\
\hline OB & $0.08 \pm 0.28$ & $0.06 \pm 0.25$ & 0.02 & 0.821 & 0.412 & 0.08 & (trivial) \\
\hline Other zone & $0.01 \pm 0.09$ & $0.01 \pm 0.06$ & 0.00 & 0.577 & 0.565 & 0.00 & (trivial) \\
\hline
\end{tabular}


Table 4. Cont.

\begin{tabular}{|c|c|c|c|c|c|c|c|}
\hline \multirow{2}{*}{ Variables } & \multicolumn{3}{|c|}{ Group } & \multicolumn{2}{|c|}{ Student $t$-Test } & \multicolumn{2}{|c|}{ Magnitude Effects } \\
\hline & Successful & Unsuccessful & Means Differences & $t$ & $P$ & $d$ & (Qualitative) \\
\hline No finalization & $0.66 \pm 0.47$ & $0.71 \pm 0.45$ & -0.05 & -1.189 & 0.236 & 0.11 & (trivial) \\
\hline \multicolumn{8}{|l|}{ Type of finalization } \\
\hline Head & $0.17 \pm 0.38$ & $0.14 \pm 0.34$ & 0.03 & 1.153 & 0.250 & 0.08 & (trivial) \\
\hline Foot & $0.17 \pm 0.37$ & $0.15 \pm 0.36$ & 0.02 & 0.499 & 0.618 & 0.06 & (trivial) \\
\hline Other body part & $0.01 \pm 0.01$ & $0.01 \pm 0.01$ & -0.00 & 0.086 & 0.932 & 0.00 & (trivial) \\
\hline No finalization & $0.66 \pm 0.47$ & $0.71 \pm 0.45$ & 0.05 & -1.283 & 0.201 & 0.11 & (trivial) \\
\hline \multicolumn{8}{|l|}{ Outcome } \\
\hline Goal & $0.08 \pm 0.27$ & $0.04 \pm 0.19$ & -0.04 & 2.132 & $0.034^{*}$ & 0.17 & (trivial) \\
\hline No goal & $0.92 \pm 0.27$ & $0.96 \pm 0.19$ & -0.04 & -2.132 & 0.034 * & 0.17 & (trivial) \\
\hline
\end{tabular}

\section{Discussion}

This study aimed to describe the patterns and outcomes of corner kicks in a Portuguese amateur team and compare successful and unsuccessful teams. This information can be used in an applied soccer setting by coaches responsible for preparing teams for corner kicks.

A total of 500 corners were analyzed, and corners were taken from the right side more predominantly than the left side, although differences did not reach statistical significance. Similar results are reported in the literature $[19,20]$. These numbers suggest a dominance of attacking down wings (slightly more on the right hand side), which is a common trend of match play. This tactical approach appears to be employed to counteract well organized defenses centrally and may be a reflection of the success that teams have when attacking in wide areas (35\% of the goals scored in EURO 2021 resulted from crosses and cut backs). This finding could also be related to the major preponderance of modern fullbacks and wingbacks [37-39]. These numbers reveal a slight predominance of play on the right side and may indicate that coaches should work on defending and attacking corners from the right hand side more frequently in training to increase successful match outcomes.

\subsection{Delivery Type}

Delivery type is widely reported in the literature as an essential variable when analyzing corner kicks [16,18-20,22,40]. More than half (54\%) were performed using an inswing trajectory from the total corner kicks, with the outswing representing $27 \%$, and short corners only $15 \%$. Several studies are consistent with these numbers, showing predominance of inswinging deliveries over outswinging and short corners [18,19,21,41]. Furthermore, [19] also highlighted the dominance of closed trajectories in the English league, regardless of whether the corner is direct $(68.8 \%)$ or indirect $(68.4 \%)$. Contrastingly, open trajectories (or outswing) were most frequent in other European leagues (Spanish, Portuguese, Italian, German, and French), especially for indirect corners [19]. Some studies [16,17,42] reported that professional teams use more outswing trajectories and bottom level inswing, which is contrary to our results. Caution must be taken when comparing this data with amateur players with studies performed with top level players. Interestingly, the different studies present different perspectives. For instance, [22] states that "even a slight touch from a defensive player could help to remove the ball from the penalty area" when referring to outswing trajectories (p. 199). Another interpretation suggests that closed trajectories can cause problems to the defending team [2]. These situations are dynamic, and coaches must choose according to their game style [43]. For example, coaches must adapt according to players' characteristics because opponents, when defending, will try to control vital 
areas such as the goalposts and it is also crucial that corners avoid goalkeeper intervention $[20,22]$. Coaches must seek other alternatives to overcome what the opponent is likely expecting [22], and the type of defending must be considered for more effective corner strategies to be adopted [41,44].

The game result must be considered. For instance, when teams are drawing and winning their perspective when defending a corner is more likely directed towards preventing the other team from scoring and not to prepare a counterattack. However, when losing, teams performed an inswing trajectory corner kick, which can illustrate a more pronounced search for a goal [19]. When the defending team are losing, they tend to take more risks to counterattack [20]. Other factors can also include the time remaining in the match, which may affect the number of attackers a team places in the opposition area to score [20].

It is interesting to notice that short or indirect corners are less frequent, but some data report this kind of option as the one that has more probability of getting a shot on goal $[18,23]$. Higher ranked teams favored short corners [17,42], in order to disrupt the opponent defensive structure [42].

\subsection{Zone and Player of the First Touch}

Central areas are the most frequently delivered into for both direct and indirect corner kicks $[16,19]$. The same was true in the present study, in which PA and GA were the most popular zones for the first ball ( $35 \%$ and $15 \%$ in GA1 and GA2, respectively; $15 \%$ and $14 \%$ in PA1 and PA2). These zones are considered a critical area, and the zone that corner takers are most likely to deliver corner kicks [22,45]. Indeed, [18,42] had similar outputs, with a more significant number of balls being headed at the near post zone, far post zone, and at the center, corresponding to PA and GA areas in the current study. The search for the central areas and first post highlights that teams from different competitive levels search predominantly for vital areas that have proven to be more effective for scoring goals [16]. The search for the posts may also reflect the tendency for coaches in the modern game to choose not to place players on the posts, especially the back post $[42,44]$. In the present study, no differences were found in the zones where the first touch occurred, with one exception: unsuccessful teams took more corners outside ( $2 \% \mathrm{vs.} 8 \%)$. This finding may be related to successful teams having technically superior players that can deliver the ball with greater accuracy. This is supported by the finding that successful teams played significantly more balls to their attackers ( $36 \%$ vs. $27 \%, p=0.022)$ and fewer balls to the defenders ( $39 \%$ vs. $50 \%, p=0.018$ ). Successful teams also wasted fewer balls (direct/outsider/fault) than unsuccessful teams ( $6 \%$ vs. $11 \%, p=0.051)$ in a near but nonsignificant difference between groups. Some studies suggest that better teams have a more consistent style of play that can provide more stability, despite other situational variables such as match location and quality of the opponent [46], and the same can be applied to set pieces as an important part of the modern game.

\subsection{Number of Attackers, Finalization Zones and Type of Finalization}

The results of the present study were consistent with other studies (five attackers were used for $58 \%$ of the corners) $[13,19,20]$, but conflicted with English Premier League players, with those teams committing more attacking players for corner kicks [16]. These findings reinforce the stylistic differences across leagues $[3,37]$. The differences may also be the result of differences in tactical approaches, with some coaches preferring balance $[14,47]$ to prevent defensive transitions [48] and/or due to having players from different competitive levels. This anticipation is a characteristic of superior level teams [49]. No statistical differences were found between the groups in our study, although successful teams used more attackers than unsuccessful teams more commonly (30\% vs. $22 \%, p=0.063)$.

In the present study, a different approach was used regarding finalization zones. The tool used to observe the zone of the first ball and the finalization zone was the same, because many times there is no direct finalization [22], and this implies that, for instance, when the first ball is played in a particular zone and after one or more rebounds, finalization is 
achieved in a different one. The most frequent finalization zones were OB, GA1, PA1, and PA2. These results differed from other studies in which more goal attempts were attained in far post areas $[22,23,42]$. It is worth noting that teams nowadays avoid placing players on the posts $(72.2 \%)$, and a goal is conceded in $3.9 \%$ of these cases, contrasting with fewer goals conceded in the corners of the goal when defenders are present on the posts [42]. The OB zone being the most used for finalization brings to light the importance of spatial occupation to improve the odds of winning a second ball after a rebound. This is also consistent with the most common finalization type, with the foot and head (16\% vs. 15\%, respectively), like in other studies [13]. When comparing the two groups, successful teams used deliveries into the GA2 area more than unsuccessful teams. However, when the ball was delivered into this area, $69 \%$ of corners did not result in finalization, and there were no differences between both groups). Further research on the conversion rate of corners when balls are delivered into certain areas appear warranted.

\subsection{Player of the First Touch and Outcome}

Corner kicks successfully and consistently delivered to a teammate are associated with promotion [40]. Our results are in line with this finding, showing that successful teams were more precise passing the ball to an attacker (36\% vs. $27 \%, p<0.05$ ). This substantiates that directing a corner kick to a teammate allows the team the first touch of the ball, increasing the number of goal-scoring attempts [22]. These findings highlight the importance of corners in the goals scored by teams that have more success across several competitions [50] and the perception of coaches to simulate more elaborate corner kicks during training sessions to be applied in the matches [3].

In our study, $31 \%$ of the 500 corners resulted in attempts at goal, with $6 \%$ of these resulting in a goal. This is slightly higher than previous studies, which range from $2.2 \%$ to $3.6 \%[13,16-18,21,22,41]$. Successful teams were more clinical in front of goal, scoring $8 \%$ of their corners, with unsuccessful teams scoring $4 \%$. This was expected because better teams have more ball possession, appear to have more shots per goal [51], and create more opportunities, and, in doing so, benefit more from offensive set pieces [50,52-54]. The results of [16] reinforce that set pieces are used by less successful teams to score, because $14.1 \%$ of goals were scored from corners, against $9.3 \%$ for the top level teams, from the study of [50]. The present study states that successful teams scored more goals and accumulate more corner kicks than unsuccessful teams. To affirm that unsuccessful teams require more corners to score, the total goals should be quantified in the present study and then how many were scored from corners determined.

As a suggestion, we would like to recommend that future studies should incorporate in their analyses techniques such as polar coordinate analysis [55,56] t-pattern analysis [57,58] or sequential analysis $[59,60]$, in order to contemplate the order/time of event execution. It would be interesting to have more studies with amateur championships, to have a deeper knowledge of these competitions that are numerous including its many players, and to our knowledge this is the first study investigating corner kicks in amateur championships.

\section{Conclusions}

The aim of this research was to analyze the corner kicks patterns of a senior football team, whilst comparing the corner kick strategies of successful and unsuccessful teams. The findings demonstrate that inswing trajectories were the most common, with the most targeted areas being central. Five players attacked most corners, although most of the corners were intercepted by a defender. A significant percentage of the corners did not result in the attacking player having an attempt at goal, with approximately $6 \%$ of corners resulting in a goal. It was also demonstrated that successful teams waste fewer corners, deliver more balls to the attackers, and are more effective at goal scoring than unsuccessful teams. This study provides novel information that can be used by coaches to inform training approaches by using the current data as a guide to practice corner kicks. It appears warranted to compare successful and unsuccessful teams from other competitions, not only 
top level, but also amateur competitions and with greater sample sizes to allow deeper comparisons and to provide valid information to coaches.

Author Contributions: V.G and J.P.D. led the project, wrote, and revised the document. V.G., H.S and J.F. collected the data. H.S., R.R.-G., R.A., N.A., A.F. and R.M. wrote and revised the original document. D.M. and J.P.D. analyzed the data. All authors have read and agreed to the published version of the manuscript.

Funding: This research was funded by the FUNDAÇÃO PARA A CIÊNCIA E TECNOLOGIA grant number UIDB/04748/2020.

Institutional Review Board Statement: The study was conducted according to the guidelines of the Declaration of Helsinki and approved by the Institutional Review Board (or Ethics Committee) of the correspondence author institution under the number L11803.

Informed Consent Statement: Not applicable.

Data Availability Statement: Data will not be shared publicly. Interested researchers may contact the corresponding author (diogo.monteiro@ipleiria.pt).

Conflicts of Interest: The authors declare no conflict of interest.

\section{References}

1. Passos, P.; Araújo, D.; Volossovitch, A. Performance Analysis in Team Sports; Routledge: London, UK, 2017.

2. Sarmento, H.; Marcelino, R.; Anguera, M.; Campaniço, J.; Matos, N.; Leitão, J. Match analysis in football: A systematic review. J. Sports Sci. 2014, 32, 1831-1843. [CrossRef]

3. Sarmento, H.; Pereira, A.; Matos, N.; Campaniço, J.; Anguera, M.; Leitão, J. English Premier League, Spains La Liga and Italy's Seriés A-What's Different? Int. J. Perform. Anal. Sport 2013, 13, 773-789. [CrossRef]

4. Anderson, C.; Sally, D. The Numbers Game: Why Everything You Know about Soccer Is Wrong; Penguin: New York, NY, USA, 2013.

5. Kubayi, A. Analysis of Goal Scoring Patterns in the 2018 FIFA World Cup. J. Hum. Kinet. 2020, 71, 205-210. [CrossRef]

6. González-Ródenas, J.; López-Bondia, I.; Aranda-Malavés, R.; Tudela, A.; Sanz-Ramírez, E.; Aranda, R. Technical, tactical and spatial indicators related to goal scoring in European elite soccer. J. Hum. Sport Exerc. 2020, 15, 186-201. [CrossRef]

7. Altarriba-Bartés, A.; Calle, M.; Susín, A.; Goncalves, B.; Vives, M.; Sampaio, J.; Peña, J. Analysis of the winning probability and the scoring actions in the American professional soccer championship. RICYDE Rev. Int. De Cienc. Del Deporte 2020, 59, 67-84. [CrossRef]

8. Njororai, W. Analysis of goals scored in the 2010 world cup soccer tournament held in South Africa. J. Phys. Educ. Sport 2013, 13, 6-13. [CrossRef]

9. Casal, C.; Maneiro, R.; Ardá, T.; Losada, J.; Rial, A. Effectiveness of Indirect Free Kicks in Elite Soccer. Int. J. Perform. Anal. Sport 2014, 14, 744-760. [CrossRef]

10. Horn, M.; Waal, S.; Kraak, W. In-match penalty kick analysis of the 2009/10 to 2018/19 English Premier League competition. Int. J. Perform. Anal. Sport 2021, 21, 139-155. [CrossRef]

11. López-García, S.; Maneiro-Dios, R.; Ardá-Suárez, A.; Rial-Boubeta, A.; Losada-López, J.; Casal-Sanjurjo, C. Indirect Free Kicks in Football High Performance. Identification of Explanatory Variables. Int. J. Med. Sci. Phys. Act. Sport 2016, 18, 247-268. [CrossRef]

12. Lago, J.; Lago, C.; Rey, E. Relevancia de las acciones a balón parado sobre los resultados en el Mundial 2006. Train. Fútbol. 2007, 134,46 .

13. Casal, C.A.; Maneiro, R.; Ardá, T.; Losada, J.L.; Rial, A. Analysis of corner kick success in elite football. Int. J. Perform. Anal. Sport 2015, 15, 430-451. [CrossRef]

14. Castelo, J. Futebol. Organização Dinâmica do Jogo, 3rd ed.; Edições Universitárias Lusófonas: Lisboa, Portugal, 2009.

15. Maneiro, R. Análisis de las Acciones a Balón Parado en el Fútbol de Alto Rendimiento: Saques de Esquina y Tiros Libres indirectos. Un Intento de Identificación de Variables Explicativas. Ph.D. Thesis, University of A Coruña, Coruña, OR, USA, 2014.

16. Strafford, B.; Smith, A.; North, J.; Stone, J. Comparative analysis of the top six and bottom six teams' corner kick strategies in the 2015/2016 English Premier League. Int. J. Perform. Anal. Sport 2019, 19, 904-918. [CrossRef]

17. Lee, J.; Mills, S. Analysis of corner kicks at the FIFA Women's World Cup 2019 in relation to match status and team quality. Int. J. Perform. Anal. Sport 2021, 5, 1-19. [CrossRef]

18. Baranda, P.; Lopez-Riquelme, D. Analysis of corner kicks in relation to match status in the 2006 World Cup. Eur. J. Sport Sci. 2012, 12, 121-129. [CrossRef]

19. Prieto-Lage, I.; Bermúdez-Fernández, D.; Paramés-González, A.; Gutiérrez-Santiago, A. Analysis of the corner kick in football in the main European leagues during the 2017-2018 season. Int. J. Perform. Anal. Sport 2021, 21, 611-629. [CrossRef]

20. Casal, C.; Losada, J.; Maneiro, R.; Ardá, T. Influence of Match Status on Corner Kick in Elite Soccer. Int. J. Med. Sci. Phys. Act. Sport 2017, 17, 715-728. [CrossRef] 
21. Borrás, D.; Baranda, P. Analysis of the corner kicks in the World Cup Korea and Japan 2002. Differences between the corner kicks in the first or in the second half of the match. CCD 2005, 2, 87-93. [CrossRef]

22. Pulling, C. Long corner kicks in the English Premier League: Delivers into the goal area and critical area. Kinesiology 2015, 47, 193-201.

23. Suárez, T.; Dios, R.; Boubeta, A.; López, J.; Sanjurjo, C. Análisis de la eficácia de los saques de esquina em la copa del mundo de fútbol 2010. Um intento de identifcación de variables explicativas. Rev. Psicol. Deporte 2014, 23, 165-172.

24. FIFA. FIFA: Professional Football Report 2019; FIFA: Zurich, Switzerland, 2019.

25. Sarmento, H.; Clemente, F.; Gonçalves, E.; Harper, L.; Dias, D.; Figueiredo, A. Analysis of the offensive process of AS Monaco professional soccer team: A mixed-method approach. Chaos Solitons Fract. 2020, 133, 109676. [CrossRef]

26. Sarmento, H.; Figueiredo, A.; Lago-Penas, C.; Milanovic, Z.; Barbosa, A.; Tadeu, P.; Bradley, P. Influence of Tactical and Situational Variables on Offensive Sequences During Elite Football Matches. J. Strength Condi. Res. 2018, 32, 2331-2339. [CrossRef]

27. Sarmento, H.; Clemente, F.; Araújo, D.; Davids, K.; McRobert, A.; Figueiredo, A. What Performance Analysts Need to Know About Research Trends in Association Football (2012-2016): A Systematic Review. Sports Med. 2018, 48, 799-836. [CrossRef]

28. Sarmento, H.; Anguera, M.; Pereira, A.; Marques, A.; Campaniço, J.; Leitão, J. Patterns of Play in the Counterattack of Elite Football Teams-A Mixed Method Approach. Int. J. Perform. Anal. Sport 2014, 14, 411-427. [CrossRef]

29. Sarmento, H.; Barbosa, A.; Campaniço, J.; Anguera, M.; Leitão, J. Regular Patterns of Play in the Counterattacks of the FC Barcelona and Manchester United FC Football Teams. In World Congress of Sport Performance Analysis IX 2012; Peters, D., O'Donoghue, P., Eds.; Routledge: Worcester, MA, USA, 2012; p. 47.

30. Fernandez, J.; Camerino, O.; Anguera, M.; Jonsson, G. Identifying and analyzing the construction and effectiveness of offensive plays in basketball by using systematic observation. Behav. Res. Methods 2009, 41, 719-730. [CrossRef] [PubMed]

31. Lapresa, D.; Álvarez, L.; Arana, J.; Garzón, B.; Caballero, V. Observational analysis of the offensive sequences that ended in a shot by the winning team of the 2010 UEFA Futsal Championship. J. Sports Sci. 2013, 31, 1731-1739. [CrossRef]

32. Camerino, O.; Chaverri, J.; Anguera, M.; Jonsson, G. Dynamics of the game in soccer: Detection of T-patterns. Eur. J. Sport Sci. 2012, 12, 216-224. [CrossRef]

33. Mueller, W.; Martorell, R. Reliability and accuracy of measurement. In Anthropometric Standardisation Reference Manual; Lohman, T.G., Roche, A.F., Martorell, R., Eds.; Human Kinetics: Champaign, IL, USA, 1988; pp. 83-86.

34. Geeta, A.; Jamaiyah, H.; Safiza, M.; Khor, G.; Kee, C.; Ahmad, A.; Faudzi, A. Reliability, technical error of measurements and validity of instruments for nutritional status assessment of adults in Malaysia. Singap. Med. J. 2009, 50, $1013-1018$.

35. Currell, K.; Jeukendrup, A. Validity, reliability and sensitivity of measures of sporting performance. Sports Med. 2008, 38, 297-316. [CrossRef]

36. Hopkins, W.; Marshall, S.; Batterham, A.; Hanin, J. Progressive statistics for studies in sports medicine and exercise science. Med. Sci. Sports Exerc. 2009, 41, 3-13. [CrossRef]

37. Mitrotasios, M.; Gonzalez-Rodenas, J.; Armatas, V.; Aranda, R. The creation of goal scoring opportunities in professional soccer. Tactical differences between Spanish La Liga, English Premier League, German Bundesliga and Italian Serie A. Int. J. Perform. Anal. Sport 2019, 19, 452-465. [CrossRef]

38. UEFA. Champions League 2020/21-Technical Report; UEFA: Nyon, Switzerland, 2021.

39. UEFA. EURO 2020-Technical Report; UEFA: Nyon, Switzerland, 2021.

40. Jamil, M.; Liu, H.; Phatak, A.; Memmert, D. An investigation identifying which key performance indicators influence the chances of promotion to the elite leagues in professional European football. Int. J. Perform. Anal. Sport 2021, 21, 641-650. [CrossRef]

41. Beare, H.; Stone, J. Analysis of attacking corner kick strategies in the FA women's super league 2017/2018. Int. J. Perform. Anal. Sport 2019, 19, 893-903. [CrossRef]

42. Kubayi, A.; Larkin, P. Analysis of teams' corner kicks defensive strategies at the FIFA World Cup 2018. Int. J. Perform. Anal. Sport 2019, 19, 809-819. [CrossRef]

43. Hewitt, A.; Greenham, G.; Norton, K. Game style in soccer: What is it and can we quantify it? Int. J. Perform. Anal. Sport 2016, 16, 355-372. [CrossRef]

44. Pulling, C.; Robins, M.; Rixon, T. Defending Corner Kicks: Analysis from the English Premier League. Int. J. Perform. Anal. Sport 2013, 13, 135-148. [CrossRef]

45. Taylor, J.; James, N.; Mellalieu, S. Notational analysis of corner kick in English Premier League soccer. In Proceedings of the Science and Football V, Proceedings of the Fifth World Congress on Science and Football, Lisbon, Portugal, 10 August 2008; Reilly, T., Cabri, J., Duarte, A., Eds.; Routledge: London, UK, 2008; pp. 229-234.

46. Bloomfield, J.; Polman, R.; O'Donoghue, P. Effects of score-line on team strategies in FA Premier League Soccer. J. Sports Sci. 2005, 23, 192-193. [CrossRef]

47. Gouveia, V. Futebol: Treinar Para Jogar; Prime Books: Lisboa, Portugal, 2019.

48. Gollan, S.; Ferrar, K.; Norton, K. Characterising game styles in the English Premier League using the "moments of play" framework. Int. J. Perform. Anal. Sport 2018, 18, 998-1009. [CrossRef]

49. Vogelbein, M.; Nopp, S.; Hokelmann, A. Defensive transition in soccer-Are prompt possession regains a measure of success? A quantitative analysis of German Fussball—Bundesliga 2010/2011. J. Sports Sci. 2014, 32, 1076-1083. [CrossRef]

50. Kubayi, A.; Toriola, A. Differentiating african teams from European teams: Identifying the key performance indicators in the FIFA World Cup 2018. J. Hum. Kinet. 2020, 73, 203-208. [CrossRef] 
51. Garratt, K.; Murphy, A.; Bower, R. Passing and goal scoring characteristics in Australian A-League football. Int. J. Perform. Anal. Sport 2017, 17, 77-85. [CrossRef]

52. Lago-Ballesteros, J.; Lago-Penas, C.; Rey, E. The effect of playing tactics and situational variables on achieving score-box possessions in a professional soccer team. J. Sports Sci. 2012, 30, 1455-1461. [CrossRef] [PubMed]

53. Castellano, J.; Casamichana, D.; Lago, C. The use of match statistics that discriminate between successful and unsuccessful soccer teams. J. Hum. Kinet. 2012, 31, 137-147. [CrossRef]

54. Hughes, M.; Franks, I. Analysis of passing sequences, shots, and goals in soccer. J. Sports Sci. 2005, 23, 509-514. [CrossRef]

55. Castañer, M.; Barreira, D.; Camerino, O.; Anguera, M.; Canton, A.; Hileno, R. Goal scoring in soccer: A polar coordinate analysis of motor skills used by Lionel Messi. Front. Psychol. 2016, 7, 806. [CrossRef] [PubMed]

56. Maneiro, R.; Amatria, M. Polar coordinate analysis of relationships with teammates, areas of the pitch, and dynamic play in soccer: A study of Xabi Alonso. Front. Psychol. 2018, 9, 389. [CrossRef]

57. Castañer, M.; Barreira, D.; Camerino, O.; Anguera, M.; Fernandes, T.; Hileno, R. Mastery in goal scoring, T-pattern detection and polar coordinate analysis of motor skills used by Lionel Messi and Cristiano Ronaldo. Front. Psychol. 2017, 8, 741. [CrossRef] [PubMed]

58. Barbosa, A.; Martins, N.; Leitão, J.; Sarmento, H.; Campaniço, J. Analysis of the existence of patterns related Counter-Attack and Fast Attack in the Spanish League 2010/2011 season. Br. J. Sport Med. 2011, 45, A11-A12. [CrossRef]

59. Sarmento, H.; Marques, A.; Martins, J.; Anguera, M.; Campaniço, J.; Leitão, J. Tactical analysis of the Barcelona counter-attack. Br. J. Sport Med. 2011, 45, A4. [CrossRef]

60. Sarmento, H.; Bradley, P.; Anguera, M.T.; Polido, T.; Resende, R.; Campaniço, J. Quantifying the offensive sequences that result in goals in elite futsal matches. J. Sports Sci. 2016, 34, 621-629. [CrossRef] 